\title{
A SEXUALIDADE PARA O ADOLESCENTE EM SITUAÇÃO DE RUA EM GOIÂNIA*
}

\author{
Marcelo Medeiros** \\ Maria das Graças Carvalho Ferriani*** \\ Denize Bouttelet Munari**** \\ Romeu Gomes*****
}

Medeiros M, Ferriani MGC, Munari DB, Gomes R. A sexualidade para o adolescente em situação de rua em Goiânia. Rev Latino-am Enfermagem 2001 março; 9(2): 35-41.

Este estudo buscou uma reflexão sobre a sexualidade do adolescente em situação de rua partindo da ótica destes. Pesquisa de abordagem qualitativa objetivando identificar aspectos gerais sobre a sexualidade de jovens que vivem nas ruas na cidade de Goiânia. Os dados foram coletados através de entrevista semi-estruturada e observação participante. Os resultados mostraram que para os meninos e meninas a sexualidade está reduzida ao ato sexual e que não se privam deste na rua sendo, a prevenção uma atitude praticamente inexistente no seu cotidiano. Apontamos para a importância do enfermeiro comprometer-se com esse grupo através de trabalhos de educação e promoção da saúde.

UNITERMOS: sexualidade, crianças de rua, adolescência

\section{THE MEANING OF SEXUALITY FOR ADOLESCENTS LIVING ON THE STREET IN GOIÂNIA}

This study aimed at reflecting on the sexuality for adolescents living on the street, based on their point of view. Authors used a qualitative approach in order to identify general aspects related to the sexuality of adolescents living on the street in Goiania. Data were collected through semi-structured interviews and participant observation. Results showed that these adolescents consider the sexuality reduced to the sexual act, and that even on the streets they are not deprived of it. Also, the prevention is a practically non-existent attitude in their daily life. Thus, authors pointed out the importance of nurses commitment to that group through health education and promotion.

KEY WORDS: sexuality, adolescents living on the street, adolescence

\section{LA SEXUALIDAD PARA EL ADOLESCENTE CALLEJERO DE GOIÂNIA}

Este estudio buscó una reflexión sobre la sexualidad de los adolescentes que viven en la calle. Investigación de abordaje cualitativo con el objetivo de identificar los aspectos generales sobre la sexualidad de los jóvenes que viven en las calles de la ciudad de Goiânia. Los datos fueron obtenidos por medio de una entrevista semi-estructurada y por observación participante. Los resultados mostraron que tanto para los hombres como para las mujeres, la sexualidad se reduce al acto sexual y que ellos no se privan de este en la calle; la prevención es

\footnotetext{
* Este trabalho é parte do projeto temático FAPESP - "Adolescência e sexualidade", do Núcleo de Ensino e Pesquisa e Assistência do Programa de Assistência Primária de Saúde Escolar (PROASE) da Escola de Enfermagem de Ribeirão Preto da Universidade de São Paulo. A execução desta pesquisa contou com o apoio do Núcleo de Estudos e Pesquisas em Saúde Integral da Faculdade de Enfermagem da Universidade Federal de Goiás (NEPSI/FEN/ UFG)

** Doutor em Enfermagem, Professor Adjunto da Faculdade de Enfermagem - Universidade Federal de Goiás. Endereço: Rua: 28-A nº 705 - Ap. 602 - Ed. Cleber Gouvea - Setor Aeroporto - 74075-500 - Goiânia - Goiás - Brasil

*** Doutora em Enfermagem, Professor Titular do Departamento de Enfermagem Materno-Infantil e Saúde Pública da Escola de Enfermagem de Ribeirão Preto da Universidade de São Paulo, Centro Colaborador da Organização Mundial da Saúde para o desenvolvimento da pesquisa em Enfermagem

**** Doutora em Enfermagem, Professor Titular da Faculdade de Enfermagem - Universidade Federal de Goiás

***** Doutor em Saúde Pública , Pesquisador Adjunto do Instituto Fernandes Figueira/FIOCRUZ
} 
una actitud prácticamente inexistente en el cotidiano de ellos. Así, nosotros señalamos lo importante que es el hecho del enfermero comprometerse con ese grupo realizando actividades de educación y promoción de la salud.

TÉRMINOS CLAVES: sexualidad, niños de la calle, adolescencia

\section{INTRODUÇÃO}

$\boldsymbol{P}_{\text {ara o adolescente, aspectos relacionados à sexualidade }}$ assumem posição de destaque em suas vidas sendo um momento importante no seu processo de formação como ser humano. Nesta fase, é imprescindível que os pais, professores e profissionais da equipe de saúde, que fazem parte do universo das relações interpessoais do adolescente, participem no sentido de contribuir para o desenvolvimento saudável da pessoa.

Entendemos, portanto, que não existe uma única definição do que é a sexualidade mas que, a partir da história pessoal e da aprendizagem social se constrói uma concepção do que é a sexualidade. Dessa forma o produto de uma construção é historicamente determinada social e culturalmente onde se apreende alguma atribuição ou mesmo o significado para as vivências práticas e experiências sexuais. Cada grupo social constrói e recria imaginário social, sobre alguns aspectos da sexualidade. Entre eles podemos citar, seu sentido, seu valor e seu papel na existência humana que, dessa forma, assume importante significado em nossas vidas se manifestando de maneiras diversa em cada pessoa e em cada cultura em momentos históricos distintos.

Historicamente, a sexualidade "foi fortemente influenciada pelas idéias cristãs, cultural, políticas e econômicas, nas quais a iniciação sexual da mulher deveria se dar no casamento e ter fins procriativos, enquanto ao homem eram permitidas as práticas sexuais e a busca do prazer fora dos limites matrimoniais"(1).

Antigamente as famílias não tinham muitas dúvidas em saber o que era certo ou errado; o que podiam permitir ou não. Hoje vivemos um momento difícil para a construção de um sistema de valores sexuais pois, ao longo das últimas décadas, a postura e o modo de perceber a sexualidade pela sociedade tem sofrido modificações substanciais ${ }^{(2)}$. Este aspecto, tem deixado pais e professores perplexos e muitas vezes em dificuldades para abordar 0 assunto com seus filhos ou alunos.

Apesar do período de transição em que vivemos, existem alguns valores que não podem deixar de ser transmitidos aos jovens, tais como o respeito por si próprio e pela sua dignidade enquanto pessoa; o respeito pelo outro pois, a ninguém é permitido ver ao outro como meio de satisfação de suas necessidades; 0 acesso à informação ${ }^{(2)}$. Responder o que a criança quer saber de forma honesta e não preconceituosa e, ainda, ajudá-la a desenvolver o espírito de crítica, a capacidade de raciocínio e a reflexão para escolher o que the convém, parece-nos a conduta mais adequada atualmente.

Um outro aspecto da sexualidade ${ }^{(1-3)}$ é que, para lidar com a sexualidade dos filhos, os pais necessitam defrontar com a própria sexualidade e esta situação pode gerar, muitas vezes, angústia. A sexualidade dos filhos traz à tona, para muitos pais, aspectos reprimidos da própria sexualidade.

Por outro lado, é na família que se desenvolve a cultura, é nela que homens e mulheres nascem, vivem, se reproduzem e morrem, dando continuidade às gerações. "É na família que surgem as bases das atividades sexuais, que são culturais mais do que inatas" ${ }^{\prime 4)}$. Para a autora é na família que se forma a estrutura psicológica do indivíduo; é no espaço familiar que fervilham as contradições e os jogos do amor e do ódio, da proteção e da violência, as disputas e os "choques de gerações".

A família, dialeticamente articulada à estrutura social, constitui-se de um espaço imprescindível para a garantia da sobrevivência, de desenvolvimento e da proteção integral de seus componentes, independentemente das múltiplas formas e desenhos que pode assumir. Nesse sentido, a família deve ser valorizada enquanto espaço essencial à produção de identidade social com vistas à formação do cidadão pois, oferece o apoio necessário ao desenvolvimento dos seus componentes, desempenha papel decisivo na educação formal e informal, absorção de valores éticos, morais e humanitários e, ainda, sedimenta o laço de solidariedade ${ }^{(5-8)}$.

Apesar dos esforços intensivos da sociedade civil organizada por meio de Organizações Não Governamentais (ONGs) ou mesmo de iniciativas públicas em buscar soluções que minimizem as conseqüências das desigualdades sociais que recaem sobre a família, nas últimas décadas a população brasileira tem vivenciado um agravamento de suas condições de vida evidenciadas pela perversidade de indicadores sociais que mostram milhares de famílias sem habitação digna, saneamento básico, trabalho, creches, enfim, sem condições de cuidar e de educar seus filhos. Nesse cenário, 40,4\% das crianças de 0 a 14 anos vivem em famílias com renda familiar per capita de até meio (1/2) salário mínimo ${ }^{(9)}$.

Assim, no Brasil atual existe uma parcela da infância e da juventude que procuram as ruas enquanto uma alternativa de sobrevivência levando em conta, entre outros fatores, as más condições de vida de sua família. Conforme verificamos, estas questões são amplamente discutidas na literatura nacional ${ }^{(10-12)}$.

Fundamentados em uma pesquisa da Fundação Sistema Estadual de Análise de Dados ${ }^{(13)}$, alguns autores ${ }^{(14)}$ apontam que a maioria das crianças que está fora da escola se insere no grupo 
etário entre onze e quatorze anos de idade, alegando principalmente motivos relacionados ao trabalho para não estar em salas de aulas. Segundo dados da Fundação Instituto Brasileiro de Geografia e Estatística, em 1994, apenas $4,1 \%$ do total de matrículas em estabelecimentos de ensino concluíram o $1^{\circ} \mathrm{grau}$ e, em 1995, $10 \%$ das crianças brasileiras de 10 a 14 anos eram analfabetas ${ }^{(9)}$.

Neste cenário observamos uma parcela significativa de crianças e adolescentes que procuram a rua para viver na esperança de escapar não só da situação de miséria e pobreza que vive suas famílias mas, também, da violência doméstica de que muitas vezes são vítimas ${ }^{(11)}$. No entanto, ali não escapam da violência urbana, da exploração no mercado informal de trabalho, do extermínio de crianças, prostituição de meninos e meninas, do problema da AIDS e sua crescente disseminação e do uso de drogas como o "crack", maconha, cocaína entre outras.

"Na década de 90, o Brasil se sobressai mundialmente, através do retrato de violência que é um misto de ideológico, étnico e social associados à pobreza, religiosidade, instabilidade política, envolvendo um crescente estado de abandono de crianças e adolescentes. Suas conseqüências se expressam através do grande contingente de meninos e meninas de rua, prostituição, pela delinqüência infanto-juvenil e pelo extermínio, vinculado à falsa ideologia da segurança interna da sociedade" ${ }^{\text {(15) }}$.

Ser criança no Brasil é, portanto, estar exposta a perigos constantes os quais entendemos por situação de risco pois, estão sujeitas ao abandono pela família e sociedade, prostituição, escravização nas minas de carvão, violência doméstica e abuso sexual, entre outras tantas possibilidades que não escolhem cor, credo ou classe social. Indica ainda o caminho para o mundo do crime como única alternativa de sobrevivência. Esta realidade confere ao Brasil um destaque entre os campeões do desamparo e maus tratos a crianças ${ }^{(16)}$.

Nesse sentido, o grupo de crianças e adolescentes que está nas ruas, cujo vínculo com a família e a escola já não existem ou estão frágeis, não conta com o apoio necessário para um desenvolvimento saudável e, com isso, descobre a sexualidade a partir da referência de colegas que estão nas ruas há mais tempo, assim como de experiências impostas por outros adolescentes ou adultos. Optamos, assim, por recortar desta realidade a questão da sexualidade de crianças e adolescentes que vivem nas ruas da cidade de Goiânia (Brasil).

\section{OBJETIVO}

Conhecer e identificar os aspectos gerais sobre a sexualidade do menino e da menina em situação de rua na cidade de Goiânia (Goiás).

\section{METODOLOGIA}

Desenvolvemos esta pesquisa à luz do referencial qualitativo, que se propõe a uma compreensão particular e profunda dos fenômenos - sociais - em questão. Mais especificamente, nossa proposta foi trabalhar de acordo com os pressupostos da Pesquisa Social, onde se refletem aspectos do desenvolvimento e da dinâmica social assim como preocupações e interesses de classes e de grupos determinados $^{(17)}$. Este referencial está fundamentado nos dados levantados através das interações interpessoais e analisados a partir da significação que os atores envolvidos atribuem aos seus atos. Portanto a Pesquisa Social não pode ser definida de forma estática ou estanque ${ }^{(17)}$ e, nesse sentido concordamos que: "Ela só pode ser conceituada historicamente e entendendo-se todas as contradições e conflitos que permeiam seu caminho. Além disso, ela é mais abrangente do que 0 âmbito específico de uma disciplina. Pois a realidade se apresenta como uma totalidade que envolve as mais diferentes áreas de conhecimento e também ultrapassa os limites da ciência" ${ }^{(17)}$.

Portanto o pesquisador deve participar, compreender e interpretar os eventos sociais de sua pesquisa, considerando o sujeito de estudo, gente, em determinada condição social, pertencente a um determinado grupo ou classe social com suas crenças, valores e significados sendo o objeto um dado que possui significados e relações que sujeitos concretos criam em suas ações ${ }^{(17)}$.

0 desenho de investigação utilizado foi o de Pesquisa Estratégica, vista por Bulmer como aquela que: "Baseia-se nas teorias das ciências sociais, mas orienta-se para problemas que surgem na sociedade, ainda que não preveja soluções práticas para esses problemas. Ela tem a finalidade de lançar luz sobre determinados aspectos da realidade"(17).

Neste trabalho elegemos as técnicas da entrevista semi-estruturada, e a observação livre. A entrevista semiestruturada consiste na combinação de um roteiro sistematizado com perguntas abertas e fechadas que permitem ao pesquisador se orientar ao elaborar as questões que pretende abordar. Tem como objetivo a descrição do caso individual, a compreensão das especificidades culturais mais profundas dos grupos e a comparabilidade dos casos. Neste tipo de entrevista, não há necessidade de uma seqüência rígida quanto aos assuntos a serem abordados porque esta é determinada, geralmente, pelas preocupações e ênfases que emergem da fala dos entrevistados ao se discutir o assunto em questão ${ }^{(17)}$. 
Analisamos as entrevistas, juntamente com nossos apontamentos, à luz da Técnica de Análise de Conteúdo, modalidade Temática, que "consiste em descobrir os 'núcleos de sentido' que compõem a comunicação e cuja presença, ou freqüência de aparição podem significar alguma coisa para o objetivo analítico escolhido"(18). Além de se buscar respostas para questões, com essa técnica pode-se caminhar na direção da "descoberta do que está por trás dos conteúdos manifestos, indo além das aparências do que está sendo analisado"(19).

A partir dessa perspectiva, inicialmente realizamos uma leitura vertical em cada entrevista, procurando apreender não só o seu conteúdo como também a sua lógica. Em seguida, através de leituras horizontais, perfilando os depoimentos um ao lado do outro, identificamos os principais aspectos das falas. Após este momento, fizemos nova leitura horizontal, estabelecendo confrontos das entrevistas e buscando núcleos de sentidos para constituirmos temáticas de análise. Por último, situando a fala no contexto sociocultural e articulando-a com as observações, procedemos à análise final.

\section{CAMPO E SUJEITOS DO ESTUDO}

A população de estudo constituiu-se de adolescentes, entre 13 e 16 anos de idade e de ambos os sexos que permanecem nas ruas a maior parte do dia na cidade de Goiânia. De acordo com as orientações da Portaria 196/96 do Conselho Nacional de Saúde que dispõe sobre pesquisas com seres humanos, obtivemos junto ao grupo pesquisado o consentimento livre e esclarecido para utilização das entrevistas no presente trabalho, uma vez que, estando nas ruas, não existe responsável oficial dos mesmos. Vale salientar que o Projeto foi cadastrado junto à Pró Reitoria de Pesquisa e Pós Graduação (29-000000-13) após parecer favorável da Comissão de Pesquisa da Faculdade de Enfermagem, ambos da Universidade Federal de Goiás.

Assim, uma vez que desenvolvemos esta pesquisa com meninos e meninas em situação de rua, optamos por apresentar alguns aspectos gerais do espaço em que vivem. 0 Estado de Goiás localiza-se ao leste da região Centro Oeste, ocupando uma área de aproximadamente $340.000 \mathrm{Km}^{2}$, tendo como limites os Estados de Tocantins ao norte, Bahia ao Leste, Minas Gerais ao leste/sudeste, Mato Grosso do Sul ao sudoeste e Mato Grosso ao Oeste.

Segundo o Datasus $^{(20)}$ no período de 1994 , a população total do Estado era de 4.240 .736 habitantes, distribuídos em 92.395 menores de um ano, 375.686 entre 1 e 4 anos, 492.529 de 5 a 9 anos de idade, 501.012 entre 10 a 14 anos, 465.943 na faixa de 15 a 19 anos e, outros 2.313 .171 maiores de 20 anos de idade. $A$ taxa de mortalidade infantil é aproximadamente 25 por mil habitantes.

0 estado de Goiás contava em 1996 com cerca de 1.015.334 estudantes distribuídos em 37.465 na pré-escola, 510.974 no primeiro grau, 62.419 no segundo grau e 18.295 no curso superior $^{(21)}$. No entanto, como já dissemos anteriormente, não foi possível acesso aos dados sobre número de escola da rede pública e privada assim como aos dados mais concretos e atualizados sobre os índices de evasão escolar.

A capital do Estado de Goiás conta hoje com aproximadamente 1.002 .377 habitantes ${ }^{(21)}$. No entanto, até o final da redação deste trabalho, a FIBGE não havia divulgado a distribuição por faixa etária de acordo com o último censo. Recorremos ao de 1991 quando a população total era de 922.222, sendo 18.723 menores de um ano, 73.847 de 1 a 4 anos, 96.739 entre cinco e nove anos, 99.374 na faixa de 10 a 14 anos e 102.852 de 15 a 19 anos e 530.687 habitantes maiores de 20 anos ${ }^{(22)}$.

Goiânia é também um centro educacional com cursos de nível superior qualificados, distribuídos nas Universidades Federal e Católica, faculdades isoladas - inclusive uma Estadual, instituições públicas e particulares de ensino pré-escolar e elementar (primeiro e segundo graus), entre várias outras de nível técnico e profissionalizante.

A economia do Estado se reflete na capital uma vez que esta concentra grande parte dos estabelecimentos comerciais e industriais, havendo no entanto, nos últimos anos uma descentralização das indústrias para o interior. A qualidade de vida do goianiense, no que tange à educação, saúde, transporte, alimentação, oferta de emprego, lazer, habitação é semelhante aos grandes centros do centro-sul do país. Porém, tanto a pobreza quanto a miséria ainda são marcantes para uma boa parcela dos habitantes da cidade e também para a população do interior, considerando ser bastante complicado o desenvolvimento urbano acompanhar o fluxo migratório campo - cidade e atender a população que chega em busca de trabalho e melhores condições de vida.

No entanto, podemos perceber que embora o Estado de Goiás possua aspectos que o caracteriza como emergente em meio ao cenário econômico, político e cultural do país, não podemos perder de vista seus traços de subdesenvolvimento, sendo as crianças e os adolescentes de famílias pobres aquelas que mais sofrem essas conseqüências, seja no âmbito familiar ou social, principalmente aquelas que vêm para a cidade em busca de melhores condições de vida e, ao chegarem, não encontram emprego, escola, habitação, tendo que se sujeitarem a viver em locais insalubres e improvisados, pedir esmolas ou ainda viver na rua com toda a família.

Nesse sentido, é crescente o número de meninos e meninas em situação de rua na cidade, mas não encontramos dados numéricos de contagens sobre os que vivem nas ruas, que estão 
nas ruas para trabalhar ou ainda que permanecem com suas famílias. Supomos que em Goiânia, cerca de 80 crianças devem fazer das ruas o espaço maior de suas vidas e mais de uma centena que estão nas ruas vadiando, trabalhando, entre outros.

Entrevistamos cinco meninos e duas meninas, de um mesmo grupo, que viviam em uma praça de bairro nobre da cidade de Goiânia. Esse número não refletiu representatividade numérica. Nossa preocupação com esta amostra qualitativa, foi "menos com a generalização e mais com o aprofundamento e abrangência da compreensão" ${ }^{(17)}$. Esse quadro de entrevistadas possibilitou análise qualitativa porque nele percebemos certa reincidência das informações.

\section{RESULTADOS E DISCUSSÃO}

Para os meninos que estão nas ruas, este espaço é o palco principal onde são estabelecidas as relações sociais entre eles próprios e, também, com a sociedade, a família, a polícia e instituições específicas de atendimento à criança e ao adolescente ${ }^{(23)}$. Nesse sentido, é no ambiente da rua que tiram seu sustento e em determinadas situações, também do grupo familiar a que pertencem.

Os entrevistados, em sua maioria, estavam nas ruas há pelo menos dois anos em caráter permanente e, com isso, praticamente não possuíam nenhum vínculo com suas famílias e não freqüentavam a escola, fatos que podem caracterizá-los como "meninos e meninas de rua". Mas em geral todos eram alfabetizados pois, quando mais novos estudaram em uma escola da rede pública porém, a leitura e escrita são bastante precárias entre estes. Apenas um deles nunca freqüentou a escola e não sabe ler ou escrever. Quanto à idade de cada um, não obtivemos dados precisos uma vez que estes não dispõem de documentação e a aparência física nem sempre a reflete com exatidão. No entanto, segundo os próprios meninos nos informaram, esta se encontra em torno dos 13 e 16 anos.

No momento da entrevista observamos que praticamente todos haviam feito uso de algum tipo de droga pois exalavam odor de solvente e a articulação das palavras estava prejudicada, embora a capacidade de raciocínio e orientação espacial e temporal estivesse preservada. No grupo entrevistado, tanto os meninos quanto as meninas abordam a questão da sexualidade de modo tranqüilo e confortável. 0 material coletado permitiu-nos identificar que, para os meninos e meninas a sexualidade está diretamente relacionada e reduzida ao ato sexual. Isto nos sugere que para eles a questão da sexualidade tem um universo próprio na rua, seguindo suas próprias determinações e significados.

Com base nos núcleos de sentidos, estruturamos os resultados a partir de unidades temáticas que são apresentadas a seguir, as quais, de uma certa forma, sintetizam os sentidos que a sexualidade assume para os sujeitos estudados.

\section{- Sexo - Prazer}

De um modo geral, as falas apontam que o sexo é bom e prazeroso, algo de bom na vida de rua:

- sexo é gostoso, me traz mais alegria, uma força mais grande, uma sensação mais boa (Menino 1); é bom esse sexo, sexual...é bom. A gente sente aquela sensação! (Menino 2); eu acho sexo muito bom, muito gostoso, um prazer que eu sinto na rua. (Menino 3).

A partir de estudo sobre 0 universo mental das crianças de rua tomando por base o que elas pensam, sentem e expressam acerca de suas experiências de vida, foram discutidos os significados no namoro e, as relações sexuais dos meninos e das meninas de rua. Conforme apontado pelos autores ${ }^{(24)}$, o namoro é uma importante forma de relacionamento onde se manifestam as atitudes a partir da referência da figura do casal parental que idealizam.

Em alguns depoimentos, como a fala de uma menina que se segue, sentimentos estão associados ao prazer:

- tem um menino aí que me chama prá transar e aí eu vou com ele porque eu gosto dele, eu amo ele. (Menina 2).

A literatura mostra também que as manifestações afetivas entre "meninos e meninas de rua" são pouco comuns e geralmente os tratamentos dispensados são ríspidos e até agressivos ${ }^{(25)}$. Geralmente as meninas, sonham com um grande amor que será capaz de mudar suas vidas e, quando estão envolvidas com algum menino, vivem intensamente aquelas experiências. Os meninos também, segundo as autoras, almejam uma relação afetiva sólida como o casamento mas a escolha da futura noiva incidirá entre aquelas que não estão nas ruas pois, estas são para casar e as que estão nas ruas não servem para o casamento. Segundo um dos meninos:

- a gente chama a menina: vamos dar uma voltinha? Aí vai... Se a gente gostar da menina bem. Se não gostar a gente leva ela também... (Menino 4).

\section{- Os Espaços do Sexo}

Segundo nos mostram as entrevistas, o fato de estarem nas ruas não é motivo para privarem-se de relações sexuais, sendo os lotes vagos e casas abandonadas os locais prediletos para 0 ato sexual, conforme podemos observar nos fragmentos a seguir:

- nos lotes vagos, em casas abandonadas, em qualquer lugar aonde der para fazer eu faço. (Menina 1); eu pratico sexo em vários locais, em casas e prédios abandonados, nesses matos, lotes vagos. (Menino 3); transo no prédio que está construindo (Menino 4); às vezes a gente não tem outro lugar então pratico sexo na rua (Menino 5). 
Foi constatado que a "transa" era vista como ato furtivo(26) Grande parte das falas das meninas estudadas apontava que 0 sexo não se praticava às claras na rua, revelando a existência de um local próprio para a sua realização. Algumas meninas chegavam a mencionar momentos do dia ou da semana menos devassados e outras falavam em lugares secretos para a prática sexual, como 0 motel. 0 sentido da fala, em geral, era o de que o sexo deve ocorrer de forma reservada, a dois.

\section{- As Transgressões e as Práticas Sexuais}

No espaço da rua, para a realização do prazer ou para a sobrevivência própria dos meninos e das meninas, podem ser identificadas práticas que, de uma forma ou de outra, transgridem as normas socialmente estabelecidas. Entre esses comportamentos, ressaltam-se a homossexualidade e trocas envolvendo favores sexuais.

Quanto às relações homossexuais, para os meninos, o papel passivo na relação é sinal de fraqueza e falta de masculinidade, não tendo caráter transitório, diferentemente das meninas para, as quais, estas experiências são circunstanciais. Apenas um dos entrevistados admite em sua fala ter, também, relações sexuais com parceiros do mesmo sexo:

- (...) eu faço sexo com gays. (Menino 1).

Alguns meninos e meninas entrevistados apontam tirar algum tipo proveito material das relações sexuais com outras pessoas que não os membros do grupo, principalmente os meninos quando recebem alguma gratificação, geralmente proveniente de adultos que podem ser tanto homens ou mulheres. Em troca de uma relação sexual podem receber algum dinheiro ou algum tipo de droga.

Eu transo com essas mulheres aí de rua... elas me dão droga, elas cheiram cola e eu também cheiro... (Menino 3).

Discussões no campo da prostituição infantil no âmbito do gênero feminino, reconhecem que isto também acontece com meninos. Aponta-se que, em geral, as meninas que compuseram sua população de estudo não faziam associação entre prostituição e prazer e, também que, se não fossem movidas por questões econômicas, a prostituição indicaria falta de moral ${ }^{(26)}$.

Esse aspecto ficou-nos bastante claro na fala de uma menina onde deixa explícito que pouco faz sexo e apenas com quem ela quer e, por isso, não se considera uma menina de programa ou prostituta. Segundo esta menina, recusa convites para atender um ou outro em troca dinheiro, embora às vezes faz isto à força quando coagida ou recebe ameaças de algum adulto ou colega da rua: - eles me levam para outros lugares, eles chamam, querem oferecer dinheiro mas, aí eu não vou não. Tem muita gente que oferece dinheiro, muitos policiais oferecem e falam assim que se agente soltar o corpo eles liberam a gente, falam de matar a gente, eles agridem a gente. (Menina 1); tem gente de fora que chama e muitas que oferecem dinheiro para mim. Os meninos já viram e me falam 'Olha, tem um homem ali te chamando para fazer programa' e eu falo que não. Dá licença que eu não vou não que eu não sou disso. Eu vou só com quem eu gosto! (Menina 2).

\section{- A Quase Ausência da Prevenção da Saúde}

Apenas um menino referiu não fazer uso de preservativo nas suas relações sexuais, sendo este aspecto omitido nas outras falas, sendo aquele que apontamos anteriormente ter admitido relações bissexuais:

- eu faço sexo sem camisinha (Menino 1).

Este é um dado bastante preocupante considerando a possibilidade da transmissão/contaminação por doenças sexualmente transmissíveis, em especial a AIDS. Segundo o Boletim Epidemiológico ${ }^{(27)}$, foram notificados no período de Janeiro de 1988 a Maio de 1998, para ambos os sexos, 599 casos de AIDS na faixa etária de 5 a 9 anos; 221 casos na faixa de 10 a 12; 199 casos na faixa de 13 a 14 anos; e 3006 casos entre adolescentes de 15 a 19 anos de idade. A vivência da sexualidade pelo adolescente pode ser uma experiência de muito prazer onde se expressam sentimentos profundos, porém existe a necessidade de que sejam tomados cuidados para que esta experiência não traga transtornos na vida pessoal e social do adolescente como por exemplo, as doenças sexualmente transmissíveis e entre elas a AIDS, assim como a gravidez indesejada ${ }^{(28)}$.

Apesar das políticas de saúde voltadas para a adolescência, trabalharem no sentido de se evitar a prática sexual por causa da transmissão de doenças e da gravidez precoce, é possível apontarmos que as ações propostas, nem sempre conseguem uma boa ressonância junto a essa faixa etária, principalmente no meio daqueles que fazem da rua de moradia e/ou trabalho.

No caso da gravidez, sendo precoce ou não, entre meninas que vivem na rua, há casos em que essa situação é bem aceita. Ao desejar ser mãe, uma menina pode estar "respondendo de forma positiva às expectativas sociais que esperam da mulher, em geral, 0 exercício da reprodução e da maternidade"(26).

\section{CONCLUSÃO}

Neste estudo não pretendíamos dar conta da complexidade que gira em torno da sexualidade dos meninos e das meninas que vivem na rua, uma vez que nosso propósito era o de conseguirmos uma abordagem exploratória inicial sobre tal assunto junto a um grupo específico que vive nas ruas da cidade de Goiânia.

Nesse sentido, em termos gerais para o grupo estudado, encontramos que a sexualidade restringe-se ao ato sexual, o qual é entendido como algo prazeroso e utilizam os espaços que a rua oferece para a sua prática. Embora não seja uma constante, a 
homossexualidade e a prostituição perpassam o universo destes meninos e meninas. Observamos também que a prática do sexo seguro não está incorporado pelo grupo.

Assim sendo, apontamos para a necessidade do desenvolvimento de um trabalho de educação em saúde para os meninos e meninas que vivem na rua, abordando a temática da sexualidade, com ênfase para os riscos dos agravos à sexualidade e a prática do sexo de um modo irresponsável e sem proteção.

Embora o enfermeiro seja um profissional qualificado técnica e cientificamente para realizar atividades educacionais, observamos que nem sempre está atento para abordar a

\section{REFERÊNCIAS BIBLIOGRÁFICAS}

1. Cano MAT. A percepção dos pais sobre sua relação com os filhos adolescentes: reflexos da ausência de perspectivas e as solicitações de ajuda. [livre-docência]. Ribeirão Preto (SP): Escola de Enfermagem de Ribeirão Preto/USP; 1997.

2. Suplicy M. Conversando sobre sexo. $17^{\mathrm{a}}$ ed. Petrópolis (RJ): Edição da Autora; 1991.

3. Cano MAT, Ferriani MGC, Munari DB. 0 trabalho de enfermeiras junto a pais de adolescentes através da atividade grupal. Rev Bras Sexualidade Humana 1995; 6(1): 36-44.

4. Guimarães T. Educação sexual na escola: mito e realidade. Campinas (SP): Companhia de Letras; 1995.

5. Forte MJP. 0 adolescente e a família. Pediatria 1996; 18(3): 15761.

6. Carvalho MCB. A priorização da família na agenda da política social. In: Kaloustian SM, organizador. Família brasileira: a base de tudo. São Paulo: Cortez; 1997. p. 93-108.

7. Ferrari M, Kaloustian SM. A importância da família. In: Kaloustioan SM, organizador. Família brasileira: a base de tudo. São Paulo: Cortez; 1997.

8. Neder G. Ajustando o foco das lentes: um novo olhar sobre a organização das famílias no Brasil. In: Kaloustian SM, organizador. Família brasileira: a base de tudo. São Paulo: Cortez; 1997. p.2646.

9. Fundação IBGE/UNICEF (BR). Indicadores sobre crianças e adolescentes: Brasil, 1991/96. Rio de Janeiro (RJ): IBGE; 1997.

10. Fausto A, Cervini R. 0 trabalho e a rua: crianças e adolescentes no Brasil urbano dos anos 80. São Paulo (SP): Cortez; 1992.

11. Minayo MCS, organizador. 0 limite da exclusão social: meninos e meninas de rua no Brasil. São Paulo (SP): HUCITEC/ABRASCO; 1993b. 12. Kaloustian SM, organizador. Família brasileira: a base de tudo. São Paulo (SP): Cortez; 1997.

13. SEADE. Fundação Sistema Estadual de Análise de Dados (BR). Crianças e adolescentes: pesquisa de condições de vida na região metropolitana de São Paulo. São Paulo (SP): SEADE; 1993. especificidade da criança e do adolescente em situação de rua no sentido de promover atividades educacionais coerentes com 0 universo desta população.

Uma programação voltada para esse propósito deve ser contemplada já na formação do profissional de enfermagem. É mais do que inclui-la nesse âmbito; defendemos a idéia de que a abordagem dada ao assunto deve, junto aos temas classicamente definidos na área da saúde pública, trabalhar princípios da ordem cultural para que as futuras ações sejam ancoradas numa interpretação cultural do conjunto das relações que se estabelecem no espaço social.

14. Medeiros M, Ferriani MGC. Programas de atenção às crianças e aos adolescentes em situação de rua: percepções de seus coordenadores. Rev Bras Crescimento Desenvolv Hum 1995; 1/2(5): 48-59.

15. Santos HO. Crianças esquecidas. Campinas (SP): Pontes; 1995. 16. Criança e adolescente: em busca da cidadania. São Paulo (SP): Conselho Regional de Psicologia; s/d.

17. Minayo MCS. 0 desafio do conhecimento: pesquisa qualitativa em saúde. São Paulo (SP): HUCITEC/ABRASCO; 1993a.

18. Bardin L. Análise de conteúdo. Lisboa (Portugal): Edições 70; 1979.

19. Gomes R. A análise de dados em pesquisa qualitativa. In: Minayo MCS, organizador. Pesquisa social: teoria, método e criatividade. Petrópolis (RJ): Vozes; 1994. p. 67-80.

20. Ministério da Saúde (BR). Datasus. População residente - Goiás por município e faixa etária, período 1994. Brasília (DF): MS; 1997. 21. Fundação IBGE (BR). Síntese de indicadores da pesquisa nacional por amostra de domićlios - 1995. Rio de Janeiro (RJ): IBGE; 1997. 22. Fundação IBGE. Censo demográfico 1991: características gerais da população e instrução, n. 27 - Goiás. Rio de Janeiro (RJ): IBGE; 1991.

23. Medeiros M. Olhando a lua pelo mundo da rua: representações sociais da experiência de vida de meninos em situação de rua. [tese]. Ribeirão Preto (SP): Escola de Enfermagem de Ribeirão Preto/USP; 1999.

24. Silva AS, Gorayeb R, Lebensztajn B, Dosin MD, Snircovsk YM. Observações sobre o universo mental das crianças de rua. Rev ABP-APAL 1991; 13(3): 85-96.

25. Fenelon GM, Martins LC, Domingues MHMS. Meninas de rua: uma vida em movimento. Goiânia (GO): CEGRAF/UFG; 1992.

26. Gomes R. 0 corpo na rua e o corpo da rua: a prostituição infantil feminina em questão. São Paulo (SP): Unimarco; 1996.

27. Ministério da Saúde (BR). Coordenação Nacional de Doenças Sexualmente Transmissíveis e AIDS. Bol Epidemiol 1998; 11(2). 28. Dias CJ. Prevenção em sexualidade na adolescência. Mundo Saúde 1997; 21(2): 75-81. 